\title{
The incidence, aetiology and outcome of acute seizures in children admitted to a rural Kenyan district hospital
} Richard Idro*1,2, Samson Gwer ${ }^{1}$, Michael Kahindi ${ }^{1}$, Hellen Gatakaa ${ }^{1}$, Tony Kazungu ${ }^{1}$, Moses Ndiritu ${ }^{1}$, Kathryn Maitland ${ }^{1,3}$, Brian GR Neville ${ }^{4}$, Piet A Kager ${ }^{5}$ and Charles RJC Newton ${ }^{1,4}$

\author{
Address: ${ }^{1}$ Centre for Geographic Medicine Research - Coast, Kenya Medical Research Institute, Kilifi, Kenya, ${ }^{2}$ Department of Paediatrics and Child \\ Health, Mulago Hospital/Makerere University, Kampala, Uganda, ${ }^{3}$ Department of Paediatrics, Faculty of Medicine and The Wellcome Trust Centre \\ for Tropical Medicine, Imperial College, London, UK, ${ }^{4}$ Neurosciences Unit, The Wolfson Centre, University College London, Institute of Child \\ Health, UK and ${ }^{5}$ Department of Infectious Diseases, Tropical Medicine and AIDS, Academic Medical Centre, Amsterdam, The Netherlands \\ Email: Richard Idro* - ridro@kilifi.kemri-wellcome.org; Samson Gwer - sgwer@kilifi.kemri-wellcome.org; \\ Michael Kahindi - mkahindi@kilifi.kemri-wellcome.org; Hellen Gatakaa - hgatakaa@kilifi.kemri-wellcome.org; \\ Tony Kazungu - tkazungu@kilifi.kemri-wellcome.org; Moses Ndiritu - mndiritu@kilifi.kemri-wellcome.org; \\ Kathryn Maitland - kmaitland@kilifi.kemri-wellcome.org; Brian GR Neville - b.neville@ich.ucl.ac.uk; Piet A Kager - p.a.kager@amc.uvl.nl; \\ Charles RJC Newton - cnewton@kilifi.kemri-wellcome.org \\ * Corresponding author
}

Published: 8 February 2008

BMC Pediatrics 2008, 8:5 doi:10.1 I86/147|-2431-8-5
Received: I October 2007

Accepted: 8 February 2008

This article is available from: http://www.biomedcentral.com/I47I-243I/8/5

C 2008 Idro et al; licensee BioMed Central Ltd.

This is an Open Access article distributed under the terms of the Creative Commons Attribution License (http://creativecommons.org/licenses/by/2.0), which permits unrestricted use, distribution, and reproduction in any medium, provided the original work is properly cited.

\begin{abstract}
Background: Acute seizures are a common cause of paediatric admissions to hospitals in resource poor countries and a risk factor for neurological and cognitive impairment and epilepsy. We determined the incidence, aetiological factors and the immediate outcome of seizures in a rural malaria endemic area in coastal Kenya.

Methods: We recruited all children with and without seizures, aged $0-13$ years and admitted to Kilifi District hospital over 2 years from Ist December 2004 to 30th November 2006. Only incident admissions from a defined area were included. Patients with epilepsy were excluded. The population denominator, the number of children in the community on $30^{\text {th }}$ November 2005 (study midpoint), was modelled from a census data.

Results: Seizures were reported in 900/4,921(18.3\%) incident admissions and at least 98 had status epilepticus. The incidence of acute seizures in children $0-13$ years was $425(95 \% \mathrm{Cl} 386,466)$ per 100,000/year and was 879 $(95 \% \mathrm{Cl} 795,968)$ per $100,000 / y e a r$ in children $<5$ years. This incidence data may however be an underestimate of the true incidence in the community. Over $80 \%$ of the seizures were associated with infections. Neonatal infections (28/43 [65.1\%]) and falciparum malaria (476/82I [58.0\%]) were the main diseases associated with seizures in neonates and in children six months or older respectively. Falciparum malaria was also the main illness (56/98 [57.1\%]) associated with status epilepticus. Other illnesses associated with seizures included pyogenic meningitis, respiratory tract infections and gastroenteritis. Twenty-eight children $(3.1 \%)$ with seizures died and II surviving children (1.3\%) had gross neurological deficits on discharge. Status epilepticus, focal seizures, coma, metabolic acidosis, bacteraemia, and pyogenic meningitis were independently associated with mortality; while status epilepticus, hypoxic ischaemic encephalopathy and pyogenic meningitis were independently associated with neurological deficits on discharge.
\end{abstract}

Conclusion: There is a high incidence of acute seizures in children living in this malaria endemic area of Kenya. The most important causes are diseases that are preventable with available public health programs. 


\section{Background}

Acute seizures are a common neurological symptom in sick children. In patients with fever, they include febrile seizures $[1,2]$, acute symptomatic seizures (e.g. in a child with pyogenic meningitis)[3] or initial seizures in a child with epilepsy or epilepsy syndrome[2].

Worldwide, febrile seizures are the most common type of acute seizures in children[4]. Most are associated with infections and have a good outcome[5]. In tropical countries, febrile seizures are common but the prevalence of acute symptomatic seizures (which have a poorer outcome) may be higher than Western countries [6-8]. The incidence of both acute seizures and febrile status epilepticus is higher[2,9] and the outcome is worse since the aetiology is different $[6,8,10,11]$. Acute seizures are therefore a major risk factor for neurological and cognitive impairment [12-14] and for the development of epilepsy [15-17] in children living in these regions. However few studies have examined the burden and risk factors for acute seizures in sub-Saharan Africa. Most of the available reports are of rates in hospital in the 1990's and are limited to the diagnoses associated with the seizure-events [18-20].

In this study, we recruited all children with incident acute seizures from a defined area in coastal Kenya admitted to a district hospital to determine the incidence, the aetiology and outcome of the seizures.

\section{Methods}

\section{Study participants}

Participants were children who were admitted with a history of acute convulsions, to Kilifi District Hospital over a period of 2 years from $1^{\text {st }}$ December 2004 to 30 th November 2006 and who were resident in a defined area in coastal Kenya. Children from the same study area but admitted without a history of seizures formed the comparison group. This hospital admits about 5000 children $<14$ years annually and is the only hospital in the area that admits very sick children. The study area undergoes a regular census three times per year and is defined by an area where over $60 \%$ of patients attending our hospital live. Each person in the study area has a unique identifier and data from hospital admissions is individually linked to the census data. However, not every child with a seizure from this community is attended to in hospital. From previous studies, just over $20 \%$ of children who had seizures in the community were admitted to the hospital (Anthony Ngugi, personal communication). The annual entomological inoculation rate (the number of times an individual is bitten by mosquitoes infected with Plasmodium falciparum in one year) in the catchment area ranges from $<1$ to 120 infectious bites per year[21].

\section{Admission procedures}

Ethical approval for the study was granted by the Kenya Medical Research Institute. Study participants were recruited consecutively as they presented to hospital. At admission, emergency care and resuscitation procedures such as correction of hypoglycaemia, hypovolaemia, oxygen and anticonvulsant therapy were administered according to Kenyan guidelines. Parents were then invited to consent to participate in the study. Children with epilepsy (two or more lifetime episodes of unprovoked seizures) were excluded. The history included the number and a parental description of the seizures. Level of consciousness was determined using the Blantyre Coma Scale [22]. Status epilepticus was defined as a seizure lasting 30 minutes or longer or as three or more seizures from which the patient did not regain consciousness after one hour[23].

About $5 \mathrm{ml}$ of venous blood was obtained for a full blood count, blood glucose, malaria parasites, microbiological culture, and plasma from children with life threatening features (acidotic breathing, shock, prostration or impaired consciousness) was obtained for acid base status, electrolytes and creatinine. The volume of blood drawn depended on the weight of the child and the ability to tolerate the blood draw. Thus, only $2 \mathrm{ml}$ was drawn from very low birth weight infants. A growth of micrococci, coagulase negative staphylococci or gram-positive Bacillus species was considered a contaminant. Severe anaemia was defined as hemoglobin $<50 \mathrm{~g} / \mathrm{L}$ and metabolic acidosis as a base deficit $>8$. Hypokalaemia was defined as plasma $\mathrm{K}^{+}<3.0 \mathrm{mmol} / \mathrm{L}$, hyperkalaemia as $\mathrm{K}^{+}>5.0 \mathrm{mmol} / \mathrm{L}$, hyponatraemia (moderate-severe) as $\mathrm{Na}^{+}<125 \mathrm{mmol} / \mathrm{L}$ and impaired renal function as plasma creatinine $>80 \mu \mathrm{mol} / \mathrm{L}$. Lumbar punctures were performed according to a standard protocol to exclude pyogenic meningitis[24]. In summary, all admissions of children aged $<60$ days with suspected sepsis, all those with impaired consciousness, children ages $<6$ months or $>6$ years with any convulsions or children with history of partial, prolonged or atypical seizures (i.e. not a simple febrile convulsion), signs of meningitis, suspected tuberculous meningitis, cryptococcal disease, acute flaccid paralysis, encephalitis or those being evaluated for CNS involvement in malignancies had lumbar puncture.

A child was said to have malaria as a primary diagnosis if $\mathrm{s}$ /he had asexual forms of $\mathrm{P}$. falciparum parasites detected on blood films and malaria was the only or main diagnosis. Children with malaria parasitaemia but admitted because of other clinical conditions (e.g. acute trauma, cardiovascular disease) were deemed to have other primary diagnoses. Malaria was treated with parenteral quinine (a loading dose of $15 \mathrm{mg} / \mathrm{kg}$ in $5 \%$ dextrose then 10 $\mathrm{mg} / \mathrm{kg} 12$ hourly until the child could take orally when 
antimalarial treatment was completed with a full course of Artemether-lumefantrine). Bacterial infections in children $\leq 2$ months were treated with a combination of Gentamicin (a loading dose of $4 \mathrm{mg} / \mathrm{kg}$ and a continuation dose of $2 \mathrm{mg} / \mathrm{kg}$ every 24 hours for babies $<2 \mathrm{~kg}$ or a loading dose of $7 \mathrm{mg} / \mathrm{kg}$ and a continuation dose of $4 \mathrm{mg} / \mathrm{kg}$ every 24 hours for babies $\geq 2 \mathrm{~kg}$ ) and Ampicillin (50 mg/ $\mathrm{kg} / 6$ hrly). For older children, crystalline penicillin (60 $\mathrm{mg} / \mathrm{kg} / 6$ hourly) and Chloramphenicol (loading dose 40 $\mathrm{mg} / \mathrm{kg}$ and a continuation dose of $25 \mathrm{mg} / \mathrm{kg} / 6$ hourly) was used. Using the above regimes, children with pyogenic meningitis received 14 days of antibiotics. Neonatal gram negative meningitis was treated for 21 days. Where resistance to the first line antibiotics was demonstrated, Ceftriaxone (or other appropriate antibiotic) was administered as $100 \mathrm{mg} / \mathrm{kg} /$ day in 2 divided doses. There were no facilities to identify viral causes of meningo-encephalitis and acyclovir was unavailable.

\section{Data management and analysis}

Individual patient clinical data was directly entered in a FileMaker 5.5 database at admission. Data was analysed using Stata version 9.2 (Stata Corporation, Texas). Using the unique patient identification numbers, the first admission during the two-year period was defined as the incident admission. The denominator, the population of children $0-13$ years was 105,992 and was obtained by modelling the census data to the date of 30 November 2005 (the midpoint of the study period). This age and sex specific estimate of the population denominator was obtained by fitting a linear regression line through the census counts (on a log scale) of October 2005 and February 2006. The incidence rates of acute seizures and status epilepticus are expressed as events per 100,000/year. A map was constructed by plotting the incidence by area of patient residence. In addition, we plotted the monthly admissions with acute seizures and compared this with the number of admissions with malaria. We then compared the clinical and laboratory features and the diagnoses in patients with and without seizures to describe the clinical risk factors for seizures and examined the risk factors for poor outcome. A poor outcome was defined as death or the presence of a gross neurological deficit/ sequela on discharge. Normally distributed continuous data were compared using the unpaired Student's t-test while skewed data were compared using Mann WhitneyWilcoxon's rank-sum test. Pearson's chi square test (or Fischer's exact test as appropriate) was used to compare proportions. Results are presented with crude odds ratios and a $\mathrm{p}$ value $<0.05$ is considered significant. To determine risk factors independently associated with mortality or neurological deficits, clinical and laboratory parameters with a p value $<0.1$ at univariate analysis were entered in a logistic regression model using a stepwise entry system.

\section{Results \\ General description}

A total of 9,960 children aged 0-13 years were admitted to $\mathrm{KDH}$ during the 2-year period. We excluded the 3,745 children from outside the study area from the analysis. In addition, 190 children with epilepsy, 36 whose residence status in the DSS could not be ascertained and 126 children not assessed for a history of seizures were excluded (figure 1).

\section{The incidence of acute seizures and status epilepticus in Kilifi DSS}

Among the remaining 5,863 admissions from the study area, there were $942(16.1 \%)$ children defined as re-admissions. These non-incident admissions were excluded from further analysis. Nine hundred (18.3\%) out of the 4,921 incident admissions had seizures. The incidence of acute seizures in children 0-13 years was 425 (95\% CI 386, $466)$ per 100,000/year and was 879 (95\% CI 795, 968) per $100,000 /$ year in children $<5$ years. The incidence was highest $(1,403$ [95\%CI 902, 2166] per 100,000/year) in neonates, lowest in infants aged 2-5 months with a second peak of 1,226 (95\% CI 1008, 1476) per 100,000/year in children 13-24 months (figure 2). At least 98(10.9\%) children with seizures had status epilepticus. The overall incidence rate of status epilepticus was 46 (95\% CI 32, 58) per 100,000/year and was 95 (95\% CI 69, 128) per $100,000 /$ year in children $<5$ years.

In general, zones nearest to the hospital had higher incidence rates of acute seizures (figure 3 ). Children with seizures were admitted throughout the year, with increases in May-August and December-January, the months that followed the long and short rains respectively (figure 4).

\section{Risk factors for acute seizures and aetiological diagnoses associated with seizures}

Clinical and laboratory features in children with acute seizures Of the 900 children with seizures, 427(47.5\%) had single seizures and the remaining $473(52.3 \%)$ had 2 or more seizures. The median number of seizures in an individual child was 2 (IQR 1-3). The median age of children admitted with seizures was higher than that of children without seizures and fewer children with seizures were severely wasted. There were no differences in gender (table 1).

A history of fever was more common in patients with seizures. The mean axillary temperature at admission was higher $\left(38.2\right.$ [SD 1.3 $\left.{ }^{\circ} \mathrm{C}\right)$ in children with seizures compared to patients without seizures (37.6 [SD 1.2 $]^{\circ} \mathrm{C}$ ), $p<$ 0.001 . However, the median duration of fever was shorter ( 2 days) in patients with seizures compared to those without seizures ( 3 days), $p<0.001$ (table 1 ). 


\section{Total number of children admitted over 2 years 9,960}

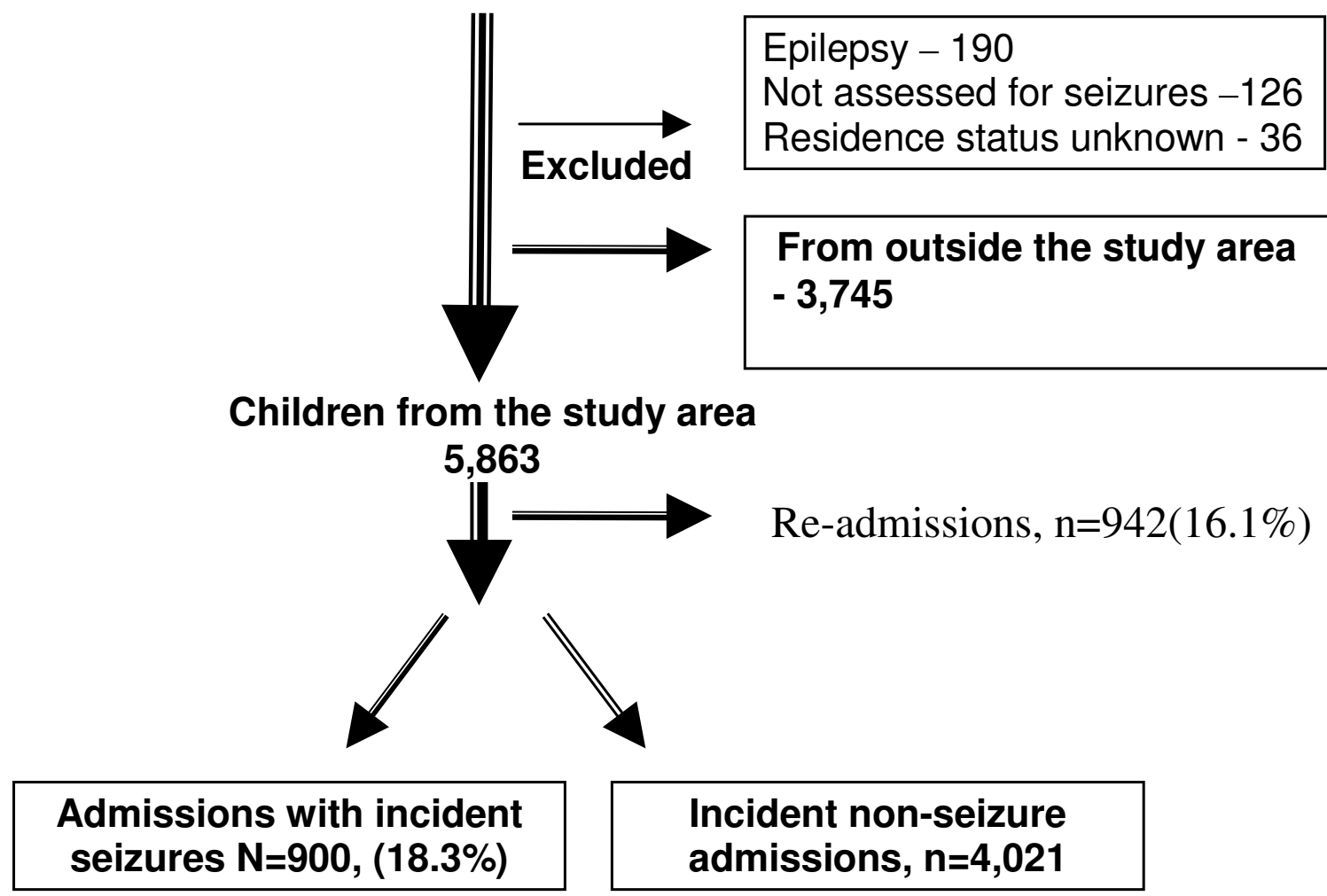

Figure I

Admissions to KDH, December 2004 to November 2006.

The median white blood cell counts and the proportions with severe anaemia were similar in both groups of patients. A total of 4,546 children had blood glucose levels determined at admission. Overall, hypoglycaemia was observed in 163 (3.6\%) patients. The proportions of patients with hypoglycaemia were similar in both groups (table 1). Of the 2,066 patients with life threatening-features who had acid base status measured, 793(38.4\%) had metabolic acidosis. The proportions of patients with metabolic acidosis admitted with and without seizures were also similar. However, impaired renal function, hypokalaemia, and moderate-severe hyponatraemia were more common in children admitted without seizures (table 1).

\section{Aetiology of acute seizures}

Over $80 \%$ of the seizures were associated with an infectious illness (table 2). Malaria was the commonest aetiological factor associated with seizures and over $50 \%$ of the children admitted with acute seizures had malaria as the primary diagnosis. The number of children with seizures and a positive malaria slide was even higher: 489/885 (55.3\%) of the children with seizures had positive malaria slides compared to $647 / 3,924(16.5 \%)$ children without seizures, $p<0.001$. The risk of seizures increased with the parasite density. Children who experienced two or more seizures had a higher geometric mean parasite density $(34,167$ [95\%CI 25,910-45,054]/ $\mu \mathrm{L})$ compared to those with single or no seizures (23,962 [95\%CI 20,135$28,517] / \mu \mathrm{L}), p<0.001$.

Apart from being the commonest illness associated with seizures, malaria was also associated with the highest seizure frequency and status epilepticus. The median number of seizures in children with malaria was 2 [IQR $1-4$ ] compared to 1 [IQR $1-3$ ], $(p=0.004)$ in those with other illnesses. Out of the 98 children with status epilepticus, malaria was the primary diagnosis in 56 (57.1\%). In addition, seizures in children with malaria had the longest duration. 


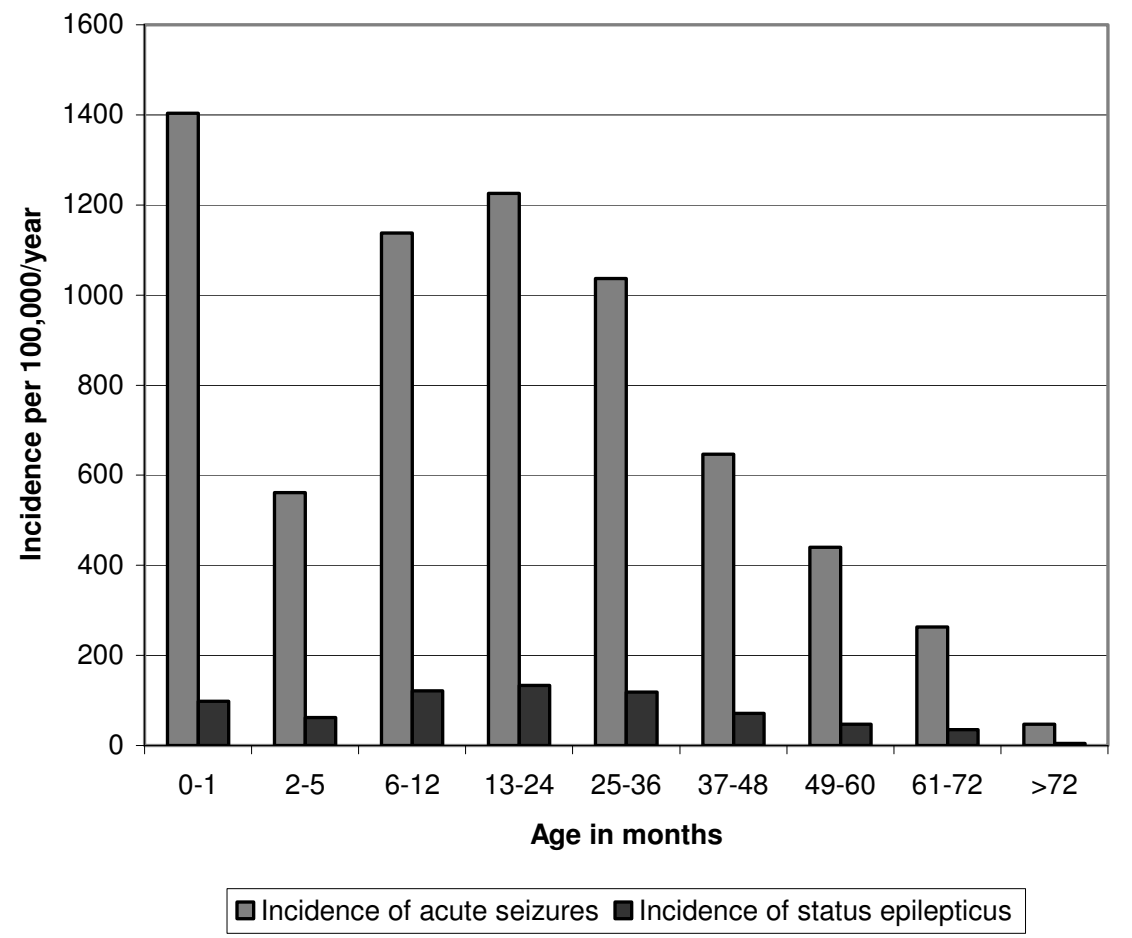

Figure 2

The incidence of acute seizures and status epilepticus by age group in children in Kilifi study area.

Two hundred and forty eight children out of 4,602 (5.4\%) had positive blood cultures but bacteraemia was more common among patients without seizures (table 1). Streptococcus pneumoniae was the commonest cause of bacteraemia in both groups of children but was more common among patients with seizures, (10/23 [43.5\%] vs 31/225 [13.8\%], p < 0.001). Other causes of bacteraemia in children with seizures included beta haemolytic Streptococci (3), Haemophilus influenzae type b (2), Escherichia coli (2), viridans Streptococci (2), non typhi Salmonella (2), Staphylococcus aureus(1) and Pseudomonas (1). Among patients without seizures bacteraemia was caused by Staphylococcus aureus, Streptococcus pneumoniae, Haemophilus influenzae, Acinetobacter, viridans Streptococci, non typhi Salmonella species and several other gram-negative rods. Lumbar puncture was performed on 594/900 (66\%) children with seizures from within the study area and a diagnosis of meningitis made in 44 children. The causes of pyogenic meningitis included Streptococcus pneumoniae (9), Haemophilus influenzae type b (2), Escherichia coli (1) and non typhi salmonella (1).

The aetiology of seizures varied with age. Sepsis was the most important cause of neonatal seizures. Pyogenic meningitis, gastroenteritis and respiratory tract infections were the most common diagnoses in children 2-5 months while malaria was the most common illness in children 6 months or older (table 3). Staphylococcus aureus, E. coli and other gram-negative rods, viridians Streptococci,Acinetobacter, and Streptococcus pneumoniae were the organisms most commonly isolated in neonatal sepsis.

\section{Immediate outcome of acute seizures}

Children admitted with seizures had a shorter hospital stay (median 3 [IQR 2-4] days) compared to patients without seizures, (4 [IQR 2-6] days), $p<0.001$. Mortality was also lower among patients with seizures compared to patients without seizures; $28 / 900(3.1 \%)$ children with seizures died compared to 225/4,021(5.4\%) children without seizures. Of the 28 deaths of children with seizures, 11 died of malaria, four of pyogenic meningitis and four possibly had viral encephalitis. Another four children had neonatal sepsis, birth asphyxia or prematurity. Table 4 is a summary of the diagnoses in patients with poor outcomes. The three other deaths were that of a preterm baby with neonatal seizures, a child with hydrocephalus and an infected shunt and another child with sickle cell disease and overwhelming sepsis.

The children with seizures who died presented to hospital after a longer median duration of illness ( 3 IQR 1, 4 days) compared to survivors (2 IQR 1, 3 days, $\mathrm{p}<0.001$ ). Pro- 


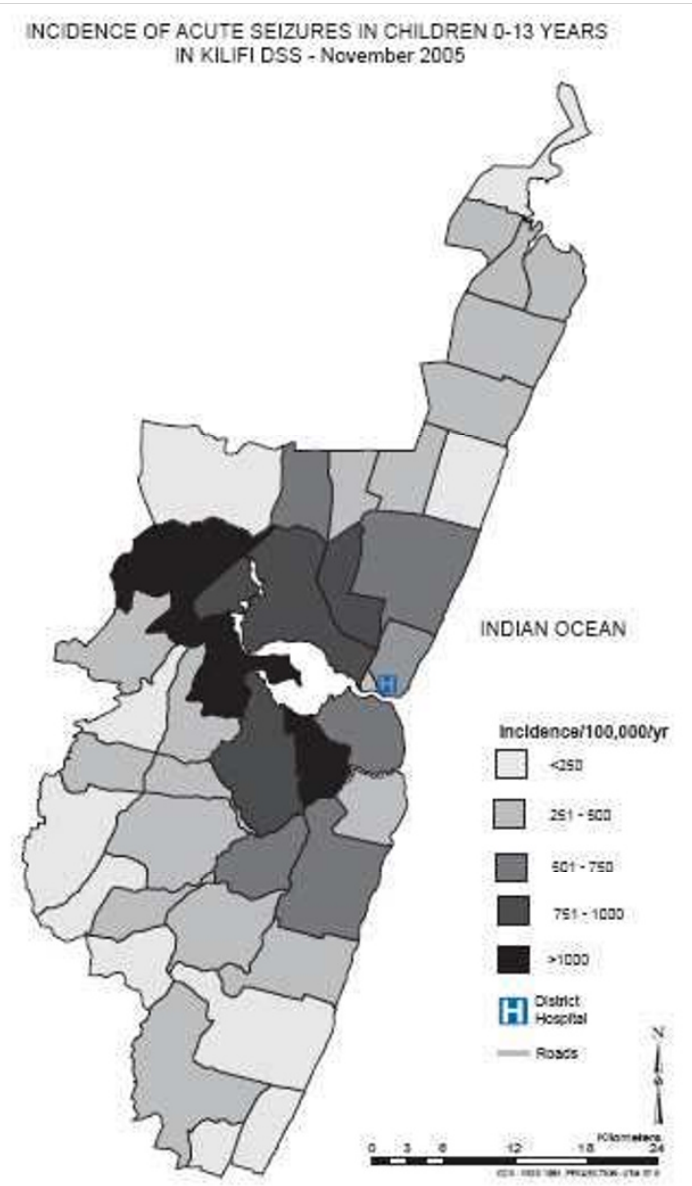

Figure 3

Incidence of acute seizures in Kilifi study area. Figure 3 is a map of Kilifi demographic surveillance area and it shows the incidence for acute seizures in the study area by sublocation. In general, the incidence is highest in areas nearest to the district hospital and decreases with distance away from the hospital.

portionally, mortality was highest in neonates, in patients admitted with coma, focal seizures or status epilepticus and among those with complications such as acidosis, hypoglycaemia, hyperkalaemia and impaired renal function, or with bacteraemia and pyogenic meningitis. The risk factors independently associated with death were coma, bacteraemia, hypoglycaemia and metabolic acidosis (table 5).

At discharge, gross neurological deficits were observed in $11 / 872(1.3 \%)$ surviving children. These included motor deficits (spasticity and central hypotonia) in 7 children, speech and hearing difficulties each in 2 children and dystonia/athetosis in one child. Neurological sequela was independently associated with coma, status epilepticus, severe wasting and hypoxic iaschemic encephalopathy (table 6).

\section{Discussion}

Children living in this rural area of Kenya experience a very high burden of acute seizure disorders. The incidence of acute seizures in children $0-13$ years was 425 per $100,000 /$ year and the incidence of non-epilepsy associated status epilepticus was 46 per 100,000 per year. Younger children were at a higher risk: the incidence of acute seizures in children younger than 5 years was 879 / $100,000 /$ year and of that of non-epilepsy associated status epilepticus was 95 per 100,000/year. Malaria and neonatal sepsis were the major aetiological factors for acute seizures and malaria for status epilepticus. Mortality was $3.1 \%$ while $1.3 \%$ of the surviving children had gross neurological deficits at the time of discharge from hospital.

\section{The incidence of acute seizures}

The incidence rate is age dependent and is highest in neonates in whom infections are the predominant cause. However, the peaks are seasonal and follow seasons of malaria transmission, which in turn is dictated by the rainfall pattern in the area. The numbers we describe excludes seizures in children with epilepsy and this incidence data is comparable to rates described in West Africa[9] except that the proportion of malaria related seizures is higher[19]. At least $11 \%$ of the children with acute seizures had status epilepticus.

This incidence data is an absolute minimum. It does not account for children from the study area that did not attend Kilifi district hospital as from previous studies, only about $20 \%$ of children who have seizures in the community are admitted to hospital (A Ngugi, personal communication) and that up to two thirds of deaths in children $<5$ years occur outside the hospital[25]. The map of incidence also suggests that distance from the hospital could have affected hospital attendance. Clearly, this suggests that our estimates could have greatly underestimated the incidence of acute seizures in children in this community. It may more closely represent the incidence of seizures in children in the study area that present for care rather the incidence of acute seizures in the region.

In a recent epidemiological study in the UK, the incidence of convulsive status epilepticus in children under the age of 16 years was estimated to be $18-20$ per 100,000 per year[26], a rate similar to that in other developed countries[27]. Despite the fact that we excluded status epilepticus associated with the epilepsies, the incidence of status epilepticus in this setting was at least twice that described in the UK. The data clearly shows that malaria accounts for the majority of the excess cases. 


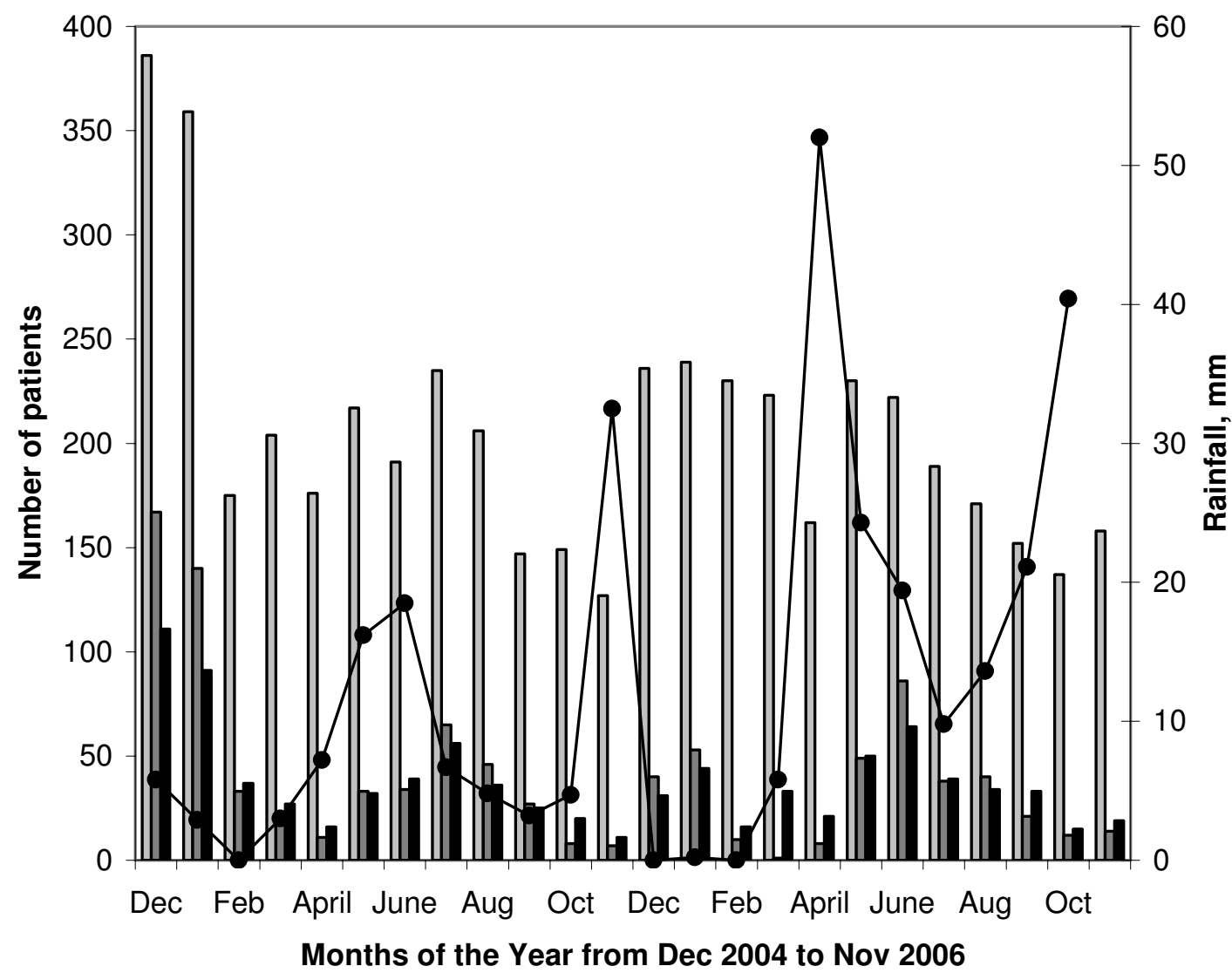

Total admissions $\square$ no. with malaria

No. with seizures $\rightarrow-$ Rainfall

\section{Figure 4}

Monthly admissions with malaria, seizures and rainfall in Kilifi. Total monthly admissions, admissions with malaria and seizures, and rainfall: The number of patients admitted with seizures has a seasonal pattern with peaks in December-January (after the short rains) and May-August (after the long rains). These peaks coincide with that for patients with presenting with malaria.

\section{Aetiological factors associated with acute seizures in children}

Infections were the predominant precipitants of acute seizures - over $80 \%$ of the seizures were associated with an infection. Malaria was not only the predominant infection in children 6 months and older but was also the main cause of status epilepticus. The median number of seizures in children infected with malaria was higher than that in children with other causes of seizures. The risk of seizures also increased with parasite density supporting the hypothesis that the parasite, Plasmodium falciparum, may be epileptogenic[28]. Sequestration of parasites in deep capillary beds in the cerebral microvasculature leading to local ischaemia/hypoxia may be responsible for this association (reviewed in[29]). Among incident cases, the association of falciparum malaria with cerebral sequestra- tion also makes it difficult to distinguish purely febrile seizures from acute symptomatic seizures.

The main causes of acute seizures in children living in this setting (malaria and neonatal infections) and other important causes (pyogenic meningitis and hypoxic ischaemic encephalopathy) are illnesses that are preventable with available public health measures. Impregnated mosquito nets and other treated mosquito materials or residual in-door spraying are proven methods for malaria control[30]. Scaling up these measures can greatly reduce the number of children exposed to malaria related seizures. Immunization against Haemophilus infleunzae type b (Hib) has virtually stopped this organism from causing severe childhood illnesses in Western countries and significant progress has already been achieved with Streptococcus pneumoniae. Improved antenatal, perinatal (delivery by 
Table I: Clinical and laboratory features on admission

\begin{tabular}{|c|c|c|c|c|}
\hline Patient characteristics & Patients with seizures & Patients without seizures & Crude OR, $(95 \% \mathrm{CI})$ & $P$ value \\
\hline Median (IQR) age, months & $25.1(|2.5,4| .4)$ & I3.I $(3.7,36.3)$ & - & $<0.001$ \\
\hline Males, $(\%)$ & $488 / 900(54.2)$ & $2,311 / 4,020(57.5)$ & $0.88(0.76,1.01)$ & 0.074 \\
\hline Median (IQR) duration of illness, days & $2(1-3)$ & $3(2-4)$ & - & $<0.001$ \\
\hline Fever, (\%) & $829 / 900(92.1)$ & $2,649 / 4,021(65.9)$ & $6.05(4.69,7.89)$ & $<0.001$ \\
\hline Severe wasting, (\%) & $12 / 900(1.3)$ & $257 / 4,019(6.4)$ & $0.20(0.10,0.35)$ & $<0.001$ \\
\hline Severe anaemia, (\%) & $56 / 900(6.2)$ & $29|/ 4,02|(7.2)$ & $0.85(0.62,1.15)$ & 0.282 \\
\hline Mean (SD) WBC, $\times 10^{3} / \mu \mathrm{l}$ & $13.8(9.9)$ & $14.0(9.5)$ & - & 0.612 \\
\hline Proportion with malaria parasitaemia, (\%) & $489 / 885(55.3)$ & $647 / 3,910(16.6)$ & $6.18(5.27,7.24)$ & $<0.001$ \\
\hline Geometric mean $(95 \% \mathrm{Cl})$ parasite density, $\times 10^{3} / \mu \mathrm{l}$ & $34.9(28.5,42.6)$ & $20.8(16.9,25.7)$ & - & $<0.001$ \\
\hline Hypoglycaemia, (\%) & $27 / 864(3.1)$ & $136 / 3,682(3.7)$ & $0.84(0.53,1.29)$ & 0.418 \\
\hline Acidosis, (\%) & $|4| / 40 \mid(35.2)$ & $652 / 1,665(39.2)$ & $0.84(0.67,1.06)$ & 0.140 \\
\hline Moderate - severe hyponatraemia, (\%) & $14 / 438(3.2)$ & $4 \mathrm{I} / 2,064(2.0)$ & $1.63(0.81,3.08)$ & 0.117 \\
\hline Hypokalaemia, (\%) & $16 / 438(3.7)$ & $243 / 2,061(11.8)$ & $0.28(0.16,0.48)$ & $<0.001$ \\
\hline Hyperkalaemia, (\%) & $37 / 438(8.5)$ & $239 / 2,061(11.6)$ & $0.70(0.48,1.02)$ & 0.056 \\
\hline Impaired renal function, (\%) & $60 / 407(14.7)$ & $408 / 1,864(21.9)$ & $0.62(0.45,0.83)$ & 0.001 \\
\hline Bacteraemia, (\%) & $23 / 882(2.6)$ & $225 / 3,720(6.1)$ & $0.42(0.26,0.64)$ & $<0.001$ \\
\hline
\end{tabular}

competent personnel and neonatal resuscitation programs) and postnatal care (cord care) can decrease the number of neonates exposed to seizures. Already, there is evidence to suggest that some of these programs are working in sub-Saharan Africa; in Kenya, there has been a drastic decline in the number of children with Haemophilus infleunzae type $b$ infections after introduction of the pentavalent (DTP-HBV-Hib) vaccine[31] and in Eritrea, the incidence rate of malaria declined by over $80 \%$ after the introduction of multiple vector control methods, case management and surveillance [32].

Infection with HIV may potentially affect the clinical presentation of children with seizures. Since November 2006 (the last month of the study period), all children admitted to the hospital were systematically tested for HIV. The results show that $8 \%$ were HIV infected. However, since our initial study protocol didn't include systematic HIV testing, we are unable to assess the effect of HIV on seizure presentation. We acknowledge this as a limitation of the study.

\section{Outcome of acute seizures}

Overall, mortality in children with seizures was low except in patients admitted with bacteraemia and neonatal infections, or those with complications such as hypoglycaemia, severe acidosis and coma. Unlike patients with malaria, pyogenic meningitis, neonatal infections or hypoxic ischaemic encephalopathy, almost all those with respiratory tract infections had single seizures and none died suggesting that these were probably febrile seizures. These febrile seizures may have contributed to the shorter dura-

Table 2: Aetiological diagnoses associated with acute seizures and outcome

\begin{tabular}{|c|c|c|c|c|}
\hline Diagnosis & $\begin{array}{l}\text { Patients with seizures, } \\
\quad(\%, n=900)\end{array}$ & $\begin{array}{l}\text { Patients without seizures, } \\
(\%, n=4,02 I)\end{array}$ & $\begin{array}{l}\text { Crude OR, } \\
(95 \% \mathrm{Cl})\end{array}$ & $P$ value \\
\hline Malaria & $479(53.2)$ & $482(12.0)$ & $8.35(7.08,9.85)$ & $<0.001$ \\
\hline Respiratory tract infections & $138(15.3)$ & $956(23.8)$ & $0.58(0.47,0.7 I)$ & $<0.001$ \\
\hline Pyogenic meningitis & $24(2.7)$ & $20(0.5)$ & $5.48(2.89,10.5)$ & $<0.001$ \\
\hline $\begin{array}{l}\text { Encephalopathy of unknown cause } \\
\text { (probable viral encephalitis) }\end{array}$ & $15(1.7)$ & $12(0.3)$ & $5.66(2.46,13.3)$ & $<0.001$ \\
\hline Gastroenteritis & $39(4.3)$ & $564(14.0)$ & $0.28(0.19,0.39)$ & $<0.001$ \\
\hline Severe malnutrition & $13(1.4)$ & $230(5.7)$ & $0.24(0.13,0.42)$ & $<0.001$ \\
\hline Trauma & $4(0.4)$ & $96(2.4)$ & $0.18(0.05,0.48)$ & $<0.001$ \\
\hline Poisoning & $I(0.1)$ & $42(1.0)$ & $0.11(0.003,0.62)$ & 0.007 \\
\hline Prematurity & $\mathrm{I}(0.1)$ & $82(2.0)$ & $0.05(0.00 I, 0.31)$ & $<0.001$ \\
\hline Hypoxic ischaemic encephalopathy & $5(0.6)$ & $98(2.4)$ & $0.23(0.07,0.55)$ & $<0.001$ \\
\hline Neonatal sepsis & $33(3.7)$ & $406(10.1)$ & $0.34(0.23,0.49)$ & $<0.001$ \\
\hline Others & $149(16.6)$ & $1,076(26.8)$ & $0.54(0.45,0.66)$ & $<0.001$ \\
\hline \multicolumn{5}{|l|}{ Outcome } \\
\hline Died & $28(3.1)$ & $226(5.6)$ & $0.54(0.35,0.8 I)$ & 0.002 \\
\hline Neurological deficits & II (I.3) & $0(0)$ & - & $<0.001$ \\
\hline
\end{tabular}


Table 3: Seizures manifestation, main aetiological factors and outcome by age group of children with seizures

\begin{tabular}{|c|c|c|c|c|c|}
\hline \multirow[t]{2}{*}{ Description of seizures } & \multicolumn{5}{|c|}{ Age group of patients } \\
\hline & $\begin{array}{l}0-\text { I month, } \\
N=43,(\%)\end{array}$ & $\begin{array}{l}2 \text { - } 5 \text { months, } \\
N=36,(\%)\end{array}$ & $\begin{array}{l}6-36 \text { months, } \\
N=535,(\%)\end{array}$ & $\begin{array}{c}37-72 \text { months, } \\
N=237(\%)\end{array}$ & $\begin{array}{l}>72 \text { months, } \\
N=49,(\%)\end{array}$ \\
\hline Proportion with seizures & $43 / 736(5.8)$ & $36 / 5 \mid 4(7.0)$ & $580 / 2,374(22.5)$ & $258 / 742(31.9)$ & $55 / 555(8.8)$ \\
\hline \multicolumn{6}{|l|}{$\begin{array}{l}\text { Parental description of } \\
\text { seizure event }\end{array}$} \\
\hline Focal & $13(30.2)$ & $7(19.4)$ & $72(13.5)$ & $21(8.9)$ & $8(16.3)$ \\
\hline $\begin{array}{l}\text { Focal, secondarily } \\
\text { generalised }\end{array}$ & $6(14.0)$ & $0(0)$ & $25(4.3)$ & $7(3.0)$ & $0(0)$ \\
\hline Generalised & $21(48.8)$ & $25(69.4)$ & $423(79.2)$ & $199(84.0)$ & 39 (79.6) \\
\hline Not described & $3(7.0)$ & $4(11.1)$ & $16(3.0)$ & $10(4.2)$ & $2(4.1)$ \\
\hline $\begin{array}{l}\text { Number of seizures, } \\
\text { median (IQR) }\end{array}$ & $3(2,5)$ & $\mathrm{I}(\mathrm{I}, 3)$ & $2(I, 3)$ & $2(1,3)$ & $I(I, 2)$ \\
\hline \multicolumn{6}{|l|}{$\begin{array}{l}\text { Level of consciousness at } \\
\text { admission }\end{array}$} \\
\hline Normal & $31(72.1)$ & $26(72.2)$ & 401 (74.9) & I7| (72.2) & $33(67.4)$ \\
\hline $\begin{array}{l}\text { Prostration or mild } \\
\text { impairment }\end{array}$ & $8(18.6)$ & $6(16.7)$ & $73(13.6)$ & $39(16.5)$ & $5(10.2)$ \\
\hline Agitation & $3(7.0)$ & $3(8.3)$ & $8(\mathrm{I} .5)$ & $3(1.3)$ & $3(6.1)$ \\
\hline Coma & $\mathrm{I}(2.3)$ & I (2.7) & $61(10.5)$ & $29(11.2)$ & $8(14.6)$ \\
\hline \multicolumn{6}{|l|}{$\begin{array}{l}\text { Leading diagnoses } \\
\text { associated with seizures by } \\
\text { age group }\end{array}$} \\
\hline 1 & $\begin{array}{c}\text { Neonatal sepsis } 28 \\
(65.1 \%)\end{array}$ & $\begin{array}{c}\text { Respiratory tract } \\
\text { infections, } 10(27.8 \%)\end{array}$ & Malaria, 303 (56.6\%) & Malaria, I55 (65.4\%) & Malaria, 18 (36.7\%) \\
\hline 2 & $\begin{array}{l}\text { Pyogenic meningitis, } 7 \\
\qquad(16.3 \%)\end{array}$ & $\begin{array}{c}\text { Acute gastroenteritis, } \\
6(16.7 \%)\end{array}$ & $\begin{array}{c}\text { Respiratory tract } \\
\text { infections, } 85 \text { (15.9\%) }\end{array}$ & $\begin{array}{c}\text { Respiratory tract } \\
\text { infections, } 37(15.6 \%)\end{array}$ & $\begin{array}{c}\text { Respiratory tract } \\
\text { infections, } 6(12.2 \%)\end{array}$ \\
\hline 3 & $\begin{array}{c}\text { Hypoxic ischaemic } \\
\text { encephalopathy, } 5 \\
\text { (1 I.6\%) }\end{array}$ & $\begin{array}{c}\text { Pyogenic meningitis, } 6 \\
\text { (16.2\%) }\end{array}$ & $\begin{array}{l}\text { Acute gastroenteritis, } \\
\qquad 27(5.1 \%)\end{array}$ & $\begin{array}{c}\text { Acute gastroenteritis, } \\
4(1.7 \%)\end{array}$ & Others 21 (42.9) \\
\hline \multicolumn{6}{|l|}{ Outcome } \\
\hline Death & $7(16.3)$ & $0(0)$ & $15(2.8)$ & $3(1.3)$ & $3(6.1)$ \\
\hline Sequelae & $3(7.0)$ & $\mathrm{I}(2.8)$ & $5(0.9)$ & $3(1.3)$ & I (2.0) \\
\hline
\end{tabular}

tion of hospital stay among patients with seizures overall since in previous studies, acute symptomatic seizures were associated with longer periods of hospitalisation [28] and increased costs of care[33] compared to children without CNS involvement. Put together, these findings suggest that the poor outcome of seizures in tropical settings[12] is related either to the severity of the illness associated with the seizures or the presence of complications such as coma, hypoglycaemia, acidosis and status epilepticus.

Table 4: Diagnosis and poor outcome in children with seizures

\begin{tabular}{lcc}
\hline Diagnosis & Mortality, (\%) & Gross Neurological deficits on discharge, (\%) \\
\hline Malaria & & $4 / 54(7.4)$ \\
$\quad$ Cerebral malaria & $9 / 63(14.3)$ & $1 / 414(0.2)$ \\
Non cerebral malaria seizures & $2 / 416(0.5)$ & $1 / 20(5.0)$ \\
Meningitis & $4 / 24(16.7)$ & $0 / 2(0)$ \\
Measles encephalitis & $2 / 4(50.0)$ & $0 / 13(0)$ \\
Encephalopathy of unknown causes & $2 / 15(13.3)$ & $1 / 31(3.2)$ \\
Neonatal infections & $2 / 33(6.1)$ & $2 / 3(66.7)$ \\
Ishemic hypoxic encephalopathy & $2 / 5(40.0)$ & $1 / 12(8.3)$ \\
Malnutrition & $1 / 13(7.7)$ & $0 / 38(0)$ \\
Gastroenteritis & $1 / 39(2.6)$ & $0 / 138(0)$ \\
Respiratory tract and ear infections & $0 / 138(0)$ & $1 / 147(0.7)$ \\
Other causes & $3 / 150(3.2)$ & $11 / 872(1.3)$ \\
Total & $28 / 900(3.1)$ & \\
\hline
\end{tabular}


Table 5: Risk factors for death among children with seizures

\begin{tabular}{|c|c|c|c|c|c|c|}
\hline Risk factors for death & Deaths, (\%) & Survivors, (\%) & $\begin{array}{l}\text { Crude Odds ratio }(95 \% \\
\mathrm{CI})\end{array}$ & P-value & $\begin{array}{c}\text { Adjusted odds ratio (95\% } \\
\mathrm{CI})\end{array}$ & $P$ value \\
\hline $\begin{array}{l}\text { Median (IQR) duration of } \\
\text { illness, days }\end{array}$ & $3(1-4)$ & $2(I-3)$ & - & 0.170 & - & - \\
\hline Median age (IQR), months & I7(3-33) & $25(13-42)$ & - & 0.048 & - & - \\
\hline Focal seizures & $8 / 25(32.0)$ & $149 / 839(17.8)$ & $2.18(0.80,5.45)$ & 0.069 & - & - \\
\hline Status epilepticus & $12 / 28(42.9)$ & $86 / 872(9.9)$ & $6.85(2.85,16.0)$ & $<0.001$ & - & - \\
\hline Coma & $14 / 28(50.0)$ & 73/872 (8.4) & II.0(4.62, 25.7) & $<0.001$ & $10.3(3.21,33.1)$ & $<0.001$ \\
\hline Severe wasting & $4 / 28(14.3)$ & $8 / 872(0.9)$ & $18.0(3.67,72.3)$ & $<0.001$ & - & - \\
\hline Severe anaemia & $4 / 28(14.3)$ & $52 / 872(6.0)$ & $2.63(0.64,8.05)$ & 0.073 & - & - \\
\hline Acidosis & $16 / 20(80.0)$ & $|25 / 38|(32.8)$ & $8.19(2.56,34.2)$ & $<0.001$ & $7.19(1.94,26.7)$ & 0.003 \\
\hline Hypoglycaemia & $6 / 27(22.2)$ & $21 / 837(2.5)$ & II.I (3.30, 33.3) & $<0.001$ & $7.06(1.73,28.7)$ & 0.006 \\
\hline Hyperkalaemia & $5 / 24(20.8)$ & $32 / 414(7.7)$ & $3.14(.86,9.45)$ & 0.025 & - & - \\
\hline Hypokalaemia & $2 / 24(8.3)$ & $|4 / 4| 4(3.4)$ & $2.60(0.27,12.4)$ & 0.209 & - & - \\
\hline Hyponatraemia & $2 / 24(8.3)$ & $|2 / 4| 4(2.9)$ & $3.05(0.31,15.0)$ & 0.141 & - & - \\
\hline Impaired renal function & I4/24 (58.3) & $46 / 383(12.0)$ & $10.3(3.94,27.2)$ & $<0.001$ & - & - \\
\hline Bacteraemia & $4 / 27(14.8)$ & $19 / 855(2.2)$ & $7.65(1.75,25.6)$ & $<0.001$ & $16.9(3.39,33.1)$ & 0.001 \\
\hline Malaria & $11 / 28(39.3)$ & $468 / 872(53.7)$ & $0.56(0.23,1.28)$ & 0.133 & - & - \\
\hline Respiratory tract infections & $0 / 28(0)$ & $138 / 872(16.4)$ & - & 0.022 & - & - \\
\hline Gastroenteritis & $1 / 28(3.6)$ & $38 / 872(4.4)$ & $0.81(0.02,5.42)$ & 0.841 & - & - \\
\hline Pyogenic meningitis & $4 / 28(14.3)$ & $20 / 872(2.3)$ & $7.1(1.63,23.5)$ & $<0.001$ & - & - \\
\hline Neonatal sepsis & $2 / 28(7.1)$ & $31 / 872(3.6)$ & $2.08(0.23,8.98)$ & 0.320 & - & - \\
\hline $\begin{array}{l}\text { Hypoxic ischaemic } \\
\text { encephalopathy }\end{array}$ & $2 / 28(7.1)$ & $3 / 872(0.3)$ & $22.3(1.77,200)$ & $<0.001$ & - & - \\
\hline
\end{tabular}

In this community, annually, at least 12 children $<5$ years per 100,000 develop gross neurological impairments following exposure to acute seizures. Status epilepticus is a prominent risk factor and malaria is the main cause of status epilepticus. The association between infection with falciparum malaria and repeated or prolonged seizures may therefore be a major risk factor for neurological impairments in children in malaria endemic Africa. Other risk factors include a background of severe malnutrition and hypoxic ischaemic encephalopathy.

\section{Conclusion}

In conclusion, children living in this rural malaria endemic area of Kenya have a high incidence of acute seizure disorders. The main causes are diseases that are preventable with available public health programs. Poor outcomes are associated with severe infection, concurrent biochemical complications, coma, status epilepticus and malnutrition.

\section{Competing interests}

The authors declare that they have no competing interests. The Wellcome Trust played no role in the design and con-

Table 6: Risk factors for neurological deficits on discharge

\begin{tabular}{|c|c|c|c|c|c|c|}
\hline Risk factors & $\begin{array}{c}\text { Deficits on } \\
\text { discharge, (\%) }\end{array}$ & $\begin{array}{l}\text { No deficits at } \\
\text { discharge, (\%) }\end{array}$ & $\begin{array}{l}\text { Crude Odds ratio } \\
(95 \% \mathrm{Cl})\end{array}$ & $P$ value & $\begin{array}{c}\text { Adjusted odds ratio } \\
(95 \% \mathrm{Cl})\end{array}$ & $P$ value \\
\hline $\begin{array}{l}\text { Median (IQR) age, } \\
\text { months }\end{array}$ & $13(0,48)$ & $26(|3,4|)$ & - & 0.644 & - & - \\
\hline Focal seizures & $1 / 1 \mid(9.1)$ & |48/828 (I7.9) & $0.46(0.01,3.28)$ & 0.449 & - & - \\
\hline Status epilepticus & $5 / 11(45.5)$ & $81 / 861(9.4)$ & $8.02(1.88,32.2)$ & $<0.001$ & $6.56(1.05,44.9)$ & 0.045 \\
\hline Coma & $4 / 11(36.4)$ & $69 / 861(8.0)$ & $6.56(1.37,26.4)$ & 0.001 & $18.4(3.03,112)$ & 0.002 \\
\hline Severe wasting & $1 / 11(9.1)$ & $7 / 861(0.8)$ & $12.2(0.24,110)$ & 0.097 & $23.9(2.15,266)$ & 0.010 \\
\hline Hypoglycaemia & $1 / I I(9.1)$ & $20 / 826(2.4)$ & $4.03(0.09,30.8)$ & 0.160 & - & - \\
\hline Malaria & $5 / 11(45.5)$ & $463 / 861(53.8)$ & $0.72(0.17,2.84)$ & 0.582 & - & - \\
\hline Bacteraemia & $1 / 11(9.1)$ & I8/844 (2.1) & $4.59(0.10,35.4)$ & 0.120 & - & - \\
\hline Pyogenic meningitis & $1 / I I(9.1)$ & $19 / 861(2.2)$ & $4.43(0.10,34.0)$ & 0.130 & - & - \\
\hline $\begin{array}{l}\text { Neonatal sepsis or } \\
\text { tetanus }\end{array}$ & $1 / I I(9.1)$ & $30 / 861(3.5)$ & $2.77(0.06,20.6)$ & 0.318 & - & - \\
\hline $\begin{array}{l}\text { Hypoxic ischaemic } \\
\text { encephalopathy }\end{array}$ & $2 / 11(18.2)$ & $\mathrm{I} / 86 \mathrm{I}(0.1)$ & $191(8.61,11278)$ & $<0.001$ & I $58(8.78,2827)$ & 0.001 \\
\hline
\end{tabular}


duct of the study, the analysis and interpretation of data or the preparation, review and approval of the manuscript.

\section{Authors' contributions}

RI designed the study, collected and analyzed the data and wrote the first draft. SG collected the data, provided clinical care for the patients and participated in data interpretation. TK, MK and HK participated in the design of the study, in data collection and in statistical analysis. MN, KM, BN and PK participated in the design of the study and interpretation of the data. $\mathrm{CN}$ participated in the design of the study, data collection, analysis and interpretation. All authors critically reviewed the manuscript.

\section{Acknowledgements}

We are grateful to the clinical and nursing staff of Kilifi District Hospital and the census staff. We specifically thank Ramos and Josephine Kazungu who stored, helped retrieve and organised the records. The Wellcome Trust sponsored this study, through funding Charles Newton as a Wellcome Trust Senior Fellowship in Clinical Tropical Medicine (No. 070 I I4).

\section{References}

I. Nelson KB Ellenberg J.H: Febrile Seizures. Edited by: Nelson KBEJH. New York, Raven Press; 198I.

2. Sadleir LG, Scheffer IE: Febrile seizures. Bmj 2007, 334(7588):307-3।I.

3. Huang CC, Chang YC, Wang ST: Acute symptomatic seizure disorders in young children--a population study in southern Taiwan. Epilepsia 1998, 39(9):960-964.

4. Hauser WA: The prevalence and incidence of convulsive disorders in children. Epilepsia 1994, 35 Suppl 2:SI-6.

5. Verity CM, Greenwood R, Golding J: Long-term intellectual and behavioral outcomes of children with febrile convulsions. $N$ Engl J Med I998, 338(24): 1723-1728.

6. Akpede GO, Abiodun PO, Sykes RM: Pattern of infections in children under-six years old presenting with convulsions associated with fever of acute onset in a children's emergency room in Benin City, Nigeria. J Trop Pediatr 1993, 39(1): I I-15.

7. Birbeck GL: Seizures in rural Zambia. Epilepsia 2000, 4I(3):277-28I.

8. Waruiru CM, Newton CR, Forster D, New L, Winstanley P, Mwangi I, Marsh V, Winstanley M, Snow RW, Marsh K: Epileptic seizures and malaria in Kenyan children. Trans R Soc Trop Med Hyg 1996, 90(2): $152-155$.

9. Iloeje SO: Febrile convulsions in a rural and an urban population. East Afr Med J 1991, 68(1):43-51.

10. Owusu-Ofori A, Agbenyega T, Ansong D, Scheld WM: Routine lumbar puncture in children with febrile seizures in Ghana: should it continue? Int J Infect Dis 2004, 8(6):353-36I.

II. Iloeje SO: Paediatric neurologic emergencies at the University of Nigeria Teaching Hospital, Enugu. West Afr J Med 1997, 16(2):80-84.

12. Carter JA, Mung'ala-Odera V, Neville BG, Murira G, Mturi N, Musumba $C$, Newton CR: Persistent neurocognitive impairments associated with severe falciparum malaria in Kenyan children. J Neurol Neurosurg Psychiatry 2005, 76(4):476-48I.

13. Boivin MJ, Bangirana P, Byarugaba J, Opoka RO, Idro R, Jurek AM, John CC: Cognitive impairment after cerebral malaria in children: a prospective study. Pediatrics 2007, I I9(2):e360-6.

14. Annegers JF, Hauser WA, Elveback LR, Kurland LT: The risk of epilepsy following febrile convulsions. Neurology 1979, 29(3):297-303.

15. Carter JA, Neville BG, White S, Ross AJ, Otieno G, Mturi N, Musumba $C$, Newton CR: Increased prevalence of epilepsy associated with severe falciparum malaria in children. Epilepsia 2004, 45(8):978-98I.

16. Ngoungou EB, Dulac O, Poudiougou B, Druet-Cabanac M, Dicko A, Mamadou Traore A, Coulibaly D, Farnarier G, Tuillas M, Keita MM,
Kombila M, Doumbo OK, Preux PM: Epilepsy as a consequence of cerebral malaria in area in which malaria is endemic in Mali, West Africa. Epilepsia 2006, 47(5):873-879.

17. Ngoungou EB, Koko J, Druet-Cabanac M, Assengone-Zeh-Nguema $Y$, Launay MN, Engohang E, Moubeka-Mounguengui M, KounaNdouongo P, Loembe PM, Preux PM, Kombila M: Cerebral malaria and sequelar epilepsy: first matched case-control study in Gabon. Epilepsia 2006, 47( (12):2147-2153.

18. Akpede GO, Sykes RM: Convulsions with fever of acute onset in school-age children in Benin City, Nigeria. J Trop Pediatr 1993, 39(5):309-3II.

19. Obi JO, Ejeheri NA, Alakija W: Childhood febrile seizures (Benin City experience). Ann Trop Paediatr 1994, I4(3):2I I-2I4.

20. Axton JH, Siebert SL: Aetiology of convulsions in Zimbabwe children three months to eight years old. Cent Afr J Med 1982, 28(10):246-249.

21. Mbogo CM, Mwangangi JM, Nzovu J, Gu W, Yan G, Gunter JT, Swalm C, Keating J, Regens JL, Shililu JI, Githure JI, Beier JC: Spatial and temporal heterogeneity of Anopheles mosquitoes and Plasmodium falciparum transmission along the Kenyan coast. Am J Trop Med Hyg 2003, 68(6):734-742.

22. Molyneux ME: The clinical features of cerebral malaria in children. Med Trop (Mars) 1990, 50(I):65-68.

23. Guidelines for epidemiologic studies on epilepsy. Commission on Epidemiology and Prognosis, International League Against Epilepsy. Epilepsia 1993, 34(4):592-596.

24. Berkley JA, Mwangi I, Ngetsa CJ, Mwarumba S, Lowe BS, Marsh K, Newton CR: Diagnosis of acute bacterial meningitis in children at a district hospital in sub-Saharan Africa. Lancet 200I, 357(9270): I753- I757.

25. Snow RW, Mung'ala VO, Foster D, Marsh K: The role of the district hospital in child survival at the Kenyan Coast. Afr J Health Sci 1994, I (2):71-75.

26. Chin RF, Neville BG, Peckham C, Bedford H, Wade A, Scott RC: Incidence, cause, and short-term outcome of convulsive status epilepticus in childhood: prospective population-based study. Lancet 2006, 368(953I):222-229.

27. Chin RF, Neville BG, Scott RC: A systematic review of the epidemiology of status epilepticus. Eur J Neurol 2004, II(I 2):800-8I0.

28. Idro R, Ndiritu M, Ogutu B, Mithwani S, Maitland K, Berkley J, Crawley J, Fegan G, Bauni E, Peshu N, Marsh K, Neville B, Newton C: Burden, features, and outcome of neurological involvement in acute falciparum malaria in Kenyan children. Jama 2007, 297(20):2232-2240.

29. Idro R, Jenkins NE, Newton CR: Pathogenesis, clinical features, and neurological outcome of cerebral malaria. Lancet Neurol 2005, 4( I 2):827-840.

30. Lengeler $C$ : Insecticide-treated bed nets and curtains for preventing malaria. Cochrane Database Syst Rev 2004:CD000363.

31. Cowgill KD, Ndiritu M, Nyiro J, Slack MP, Chiphatsi S, Ismail A, Kamau T, Mwangi I, English M, Newton CR, Feikin DR, Scott JA: Effectiveness of Haemophilus influenzae type b Conjugate vaccine introduction into routine childhood immunization in Kenya. Jama 2006, 296(6):67I-678.

32. Mufunda J, Nyarango P, Usman A, Gebremeskel T, Mebrahtu G, Ogbamariam A, Kosia A, Ghebrat Y, Gebresillosie S, Goitom S, Araya E, Andemichael G, Gebremichael A: Roll back malaria--an African success story in Eritrea. S Afr Med J 2007, 97(I):46-50.

33. Kirigia JM, Snow RW, Fox-Rushby J, Mills A: The cost of treating paediatric malaria admissions and the potential impact of insecticide-treated mosquito nets on hospital expenditure. Trop Med Int Health 1998, 3(2): I45-I 50.

\section{Pre-publication history}

The pre-publication history for this paper can be accessed here:

http://www.biomedcentral.com/1471-2431/8/5/prepub 